\title{
The study on mechanical properties of cement mortar with different types of steel fibers
}

\author{
HaiLong Zhang \\ Department of Structural Engineering, College of \\ Engineering, Yanbian University, \\ Yanji, 133002, China \\ jxxf-aqq@163.com
}

\begin{abstract}
*Author: HaiLong Zhang(1988-) is a male current master student from Zhangjiakou city, Hebei province, China. The main research area is principles and application of concrete structures.
\end{abstract}

\begin{abstract}
In this paper, we study the effects on mechanical properties of cement mortar with different types of steel fibers. The results showed that: (1)Among the three kinds of cement mortars mixed with different steel fibers, the apparent density of mortar mixed with type-C was the minimum, and turned out a steady growth trend as increasing of volume ratio. (2) The flexural strength of mortar mixed with steel fibers was significantly higher than OPC. When the age was $28 \mathrm{~d}$, the flexural strength of mortar mixed with $\mathrm{C}$-type steel fiber was the maximum, showing a strong 'anchor' performance. (3) The contribution on the compressive strength of the steel fiber' type and volume ratio was small. Of the three types of mortar, the compressive strength mixed with type-B got a higher value. In the age of 28d, the compressive strength of mortar mixed with type-B got the highest value. (4)The flexural properties of mortar mixed with type-C would be further improved with the increase of mortar matrix' strength. For the tensile, flexural properties of high strength concrete, improving its toughness and bending performance requires more steel fiber's content than ordinary concrete.
\end{abstract}

Keywords-steel fiber; ends-structure; volume ratio; mechanical properties; anchor

\section{INTRODUCTION}

Steel fiber reinforced concrete with good mechanical and durability has gotten much concern and attention of the majority of scholars and engineers. As a result, the study of steel fiber reinforced concrete has made great achievements. The steel fiber in concrete can effectively prevent the expansion of cracks inside the concrete, and improve the performance of tensile, flexural, impact and fatigue resistance. Therefore, a reasonable choice of types, incorporation rate, shape and size of steel fiber is the key to increase the mechanical and durability of steel fiber reinforced concrete [1-3]. This article produced a closedtype hook by changing the ends structure of fiber to raise the anchor role in enhancing the effect of interfacial adhesion between mortar and steel fibers. The method can give full play to the tensile properties of steel fibers to improve the mechanical properties of mortar, and provide

\author{
ChangChun Pei* \\ Department of Structural Engineering, College of \\ Engineering, Yanbian University, \\ Yanji, 133002, China \\ peicc@ybu.edu.cn
}

Corresponding Author: ChangChun Pei(1976-) is a male Doctor(Master Instructor) from Yanji city, Jilin province, China. The main research area is principles and application of concrete structures.

a theoretical reference for the future application of steel fibers in concrete structures.

\section{EXPERIMENTAL PROGRAM AND METHODS}

\section{A. Experimental Design}

The experiment took $0 \%$ of steel fiber in ordinary cement mortar (the OPC) as the reference mortar, with 0.35 of water-cement ratio. Others were incorporated into the reference mortar with three types of steel fibers, type-A (once hook of both ends), type-B (two hook of both ends), and type- $\mathrm{C}$ (closed type of both ends), given in Fig .1. The volume content of steel fiber was design as $0.5 \%, 1.0 \%$ and $1.5 \%$ [4-7]. A group of 10 experiments were designed, and measured the apparent density of cement mortar in the plastic state and the compressive strength and flexural

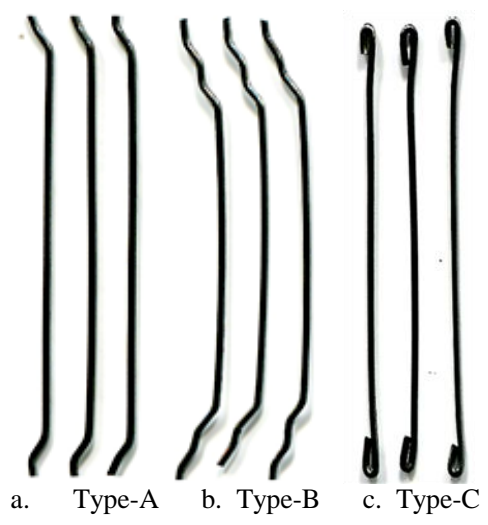

Figure 1. The ends Structure of Steel Fiber

strength of different age in the hardened state. The mortar mix was shown in Table 1.

\section{B. Experimental Material}

The cement used in this experiment was ordinary portland cement of Wang Qing city, Jilin province, with the density of $3115 \mathrm{~kg} / \mathrm{m} 3$. The steel fibers type-A and type-B were sold on the market, and type-C of improvement ends of closed were made in laboratory, with length of $50 \mathrm{~mm}$, and aspect ratio of 60 . The 
polycarboxylate superplasticizer was the production of

TABLE I. DESIGN OF MIX

\begin{tabular}{cccccc}
\hline Notation & Water-cement ratio & Mortar than & Type of steel fiber & Blended rate/\% & Superplasticizer/\% \\
\hline OPC & 0.35 & $1: 3$ & - & 0.0 & 1.2 \\
SF-A-0.5 & 0.35 & $1: 3$ & A & 0.5 & 1.2 \\
SF-A-1.0 & 0.35 & $1: 3$ & A & 1.0 & 1.2 \\
SF-A-1.5 & 0.35 & $1: 3$ & A & 1.5 & 1.2 \\
SF-B-0.5 & 0.35 & $1: 3$ & B & 0.5 & 1.2 \\
SF-B-1.0 & 0.35 & $1: 3$ & B & 1.0 & 1.2 \\
SF-B-1.5 & 0.35 & $1: 3$ & B & 1.5 & 1.2 \\
SF-C-0.5 & 0.35 & $1: 3$ & C & 0.5 & 1.2 \\
SF-C-1.0 & 0.35 & $1: 3$ & C & 1.0 & 1.2 \\
SF-C-1.5 & 0.35 & $1: 3$ & C & 1.5 & 1.2 \\
\hline
\end{tabular}

Qing Dao city, with reduction of $25 \%$, proportion of 1.08 \pm 0.02 , and solid content of $20 \pm 1 \%$. The sand used in this experiment was the production of natural sand from Yanji, Jilin Province, with density of $2650 \mathrm{~kg} / \mathrm{m} 3$.

\section{Experimental Methods}

This test used UJZ-15B-type mortar mixer. Firstly, cement and sand were stirred 120s. At the same time, steel fibers were evenly thrown into the mixer. Secondly, the mixture of water and superplasticizer was added into it, and stirred 300s. Apparent density was determined by JTGE30-2005 'Highway Engineering Cement and Concrete test procedures' . Test block was placed in BYS- II type curing room after forming, and measured for flexural strength and compressive strength of different age according to GB/T 17671-2005 [8] ' cement mortar strength detection method'. Flexural strength (Rf) was calculated as formula (1) (accurate to $0.1 \mathrm{MPa}$ ):

$\mathrm{Rf}=1.5 \mathrm{FfL} / \mathrm{b} 3$

Ff- failure load, N; L- the center distance of support cylinder, $\mathrm{mm}$; $\mathrm{b}$ - the side length of prism square section, $\mathrm{mm}$.

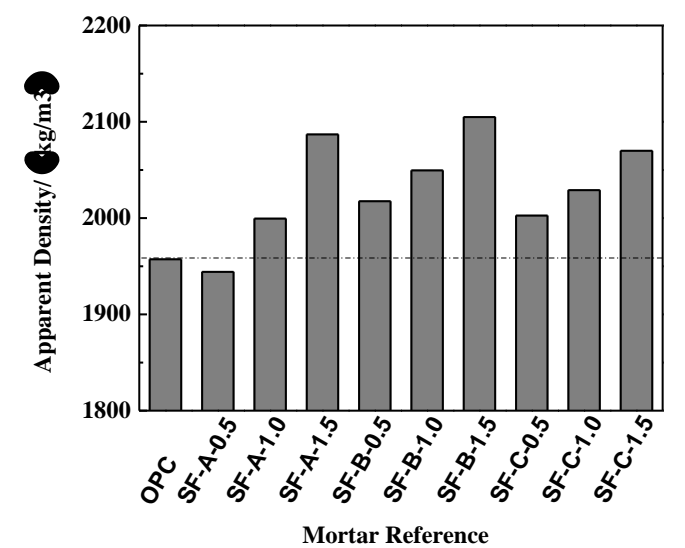

Figure 2. The apparent density of cement mortar with different types of steel fiber

\section{RESULTS AND DISCUSSION}

\section{A. Apparent density}

As shown in Fig .2, took the apparent density of ordinary cement mortar (OPC) as basic standards, the apparent density of cement mortar mixed with different types of steel fibers were higher than OPC, and they were as high as the content increases of steel fibers. Among them, the apparent density of the incorporation of $1.5 \%$ type-B (SF-B-1.5) was the maximum value, $2105 \mathrm{~kg} / \mathrm{m} 3$, followed by SF-A-1.5, 2087kg/m3, SF-C-1.5, 2070kg/m3.

\section{B. Flexural strength}

As shown in Fig .3 and Fig .4, when the age was 3d, the flexural strength of OPC was 6.1MPa. With the different steel fibers incorporated, only the flexural strength of SF-A-0.5 was slightly less than OPC, and the others were all higher than OPC. For different steel fiber reinforced mortar, the flexural strength had a tendency to increase as the increase of steel fiber content. Among them, the flexural strength of SF-A-1.5 got the maximum value, $11.9 \mathrm{MPa}$, reached $196 \%$ of OPC, followed by SF-C-1.5, 10.5MPa, SF-B-1.5, 10.2MPa. They were all higher than the early strength values. Experimental research and engineering practice shows that, for the ordinarily strength of fiber reinforced concrete, premature failure of the interfacial adhesion caused that thereby reinforcing fibers are not fully play the role and reduced the enhancement effect [1].

When the age was $7 \mathrm{~d}$, the flexural strength of OPC was 6.7 MPa. In addition to the flexural strength of SF-A-0.5, the rest flexural strength of mortar mixed with steel fiber was all higher than OPC. With the growth of age, compared with the flexural strength of $3 \mathrm{~d}$, the flexural strength of cement mortar mixed with three kinds of steel fibers was greatly improved. This is because that as the increasing strength of cement matrix, the adhesion between fibers and matrix was being gradually improved, and the flexural strength of test blocks had been greatly increased. 
When the age was $28 \mathrm{~d}$, the flexural strength of OPC was $6.7 \mathrm{MPa}$, and closed to $7 \mathrm{~d}$. Compared with the age of $7 \mathrm{~d}$, the flexural strength of mortar mixed with steel fibers type-A and type-B had little change, even had a small amount of strength loss. However, compared with the age of $7 \mathrm{~d}$, the mortar mixed with type-C had greatly improved.

The flexural strength of SF-C-1.0 was $15.4 \mathrm{MPa}$, $131.3 \%$ higher than OPC, and the flexural strength of SF-

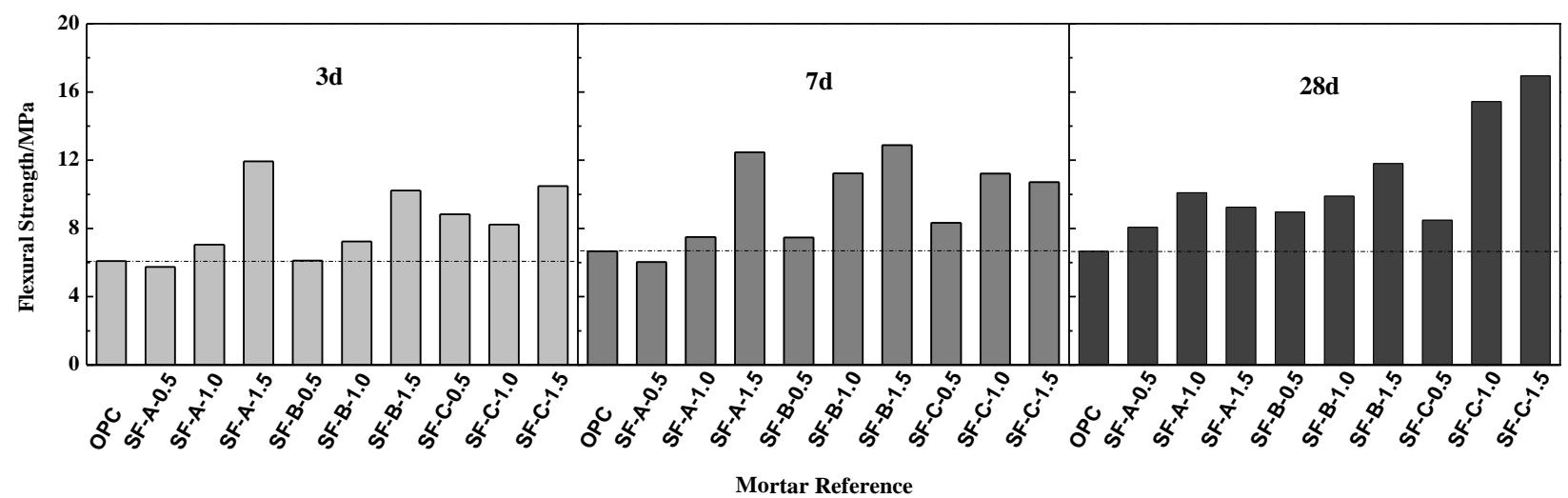

Figure 3. The flexural strength of cement mortar with different types of steel fiber

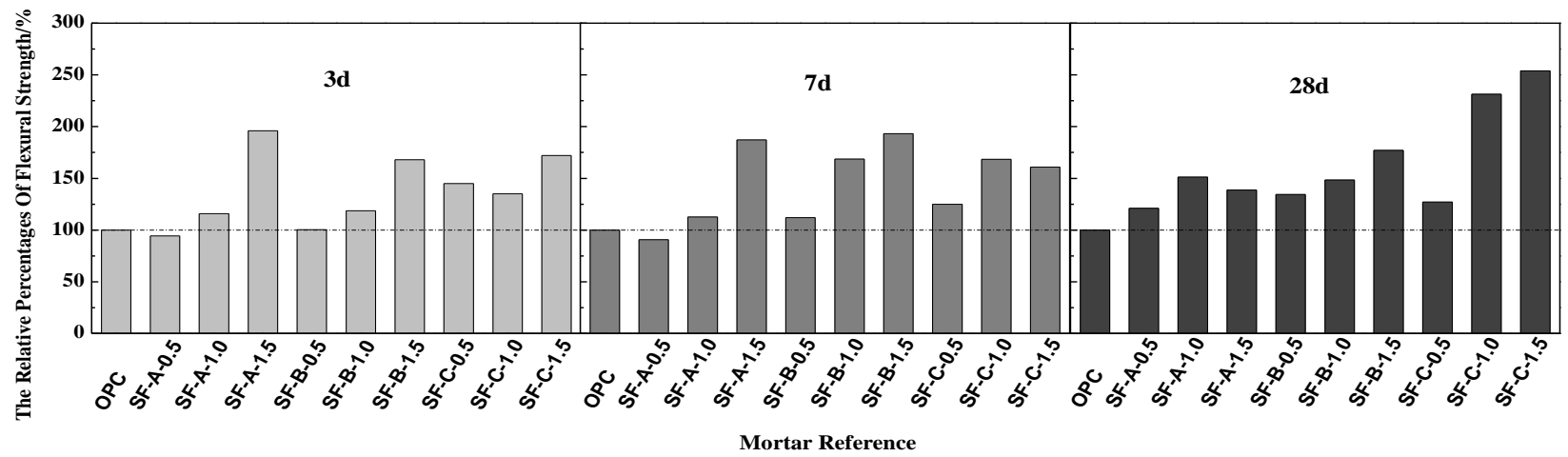

Figure 4. The relative percentages of flexural strength of cement mortar with different types of steel fiber

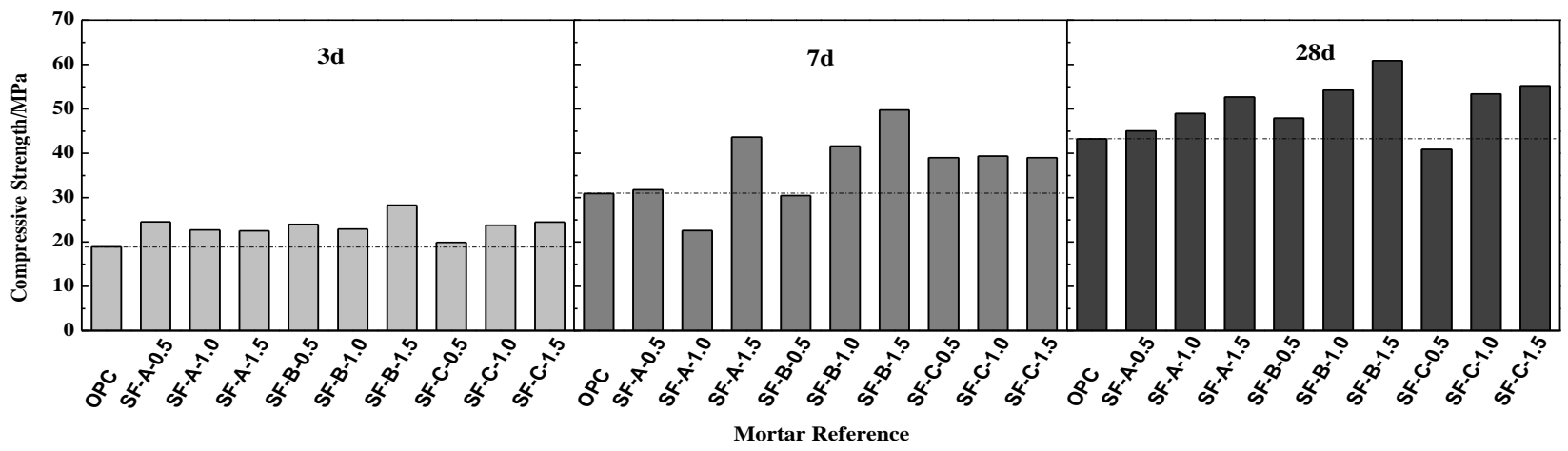

Figure 5. The compressive strength of cement mortar with different types of steel fiber

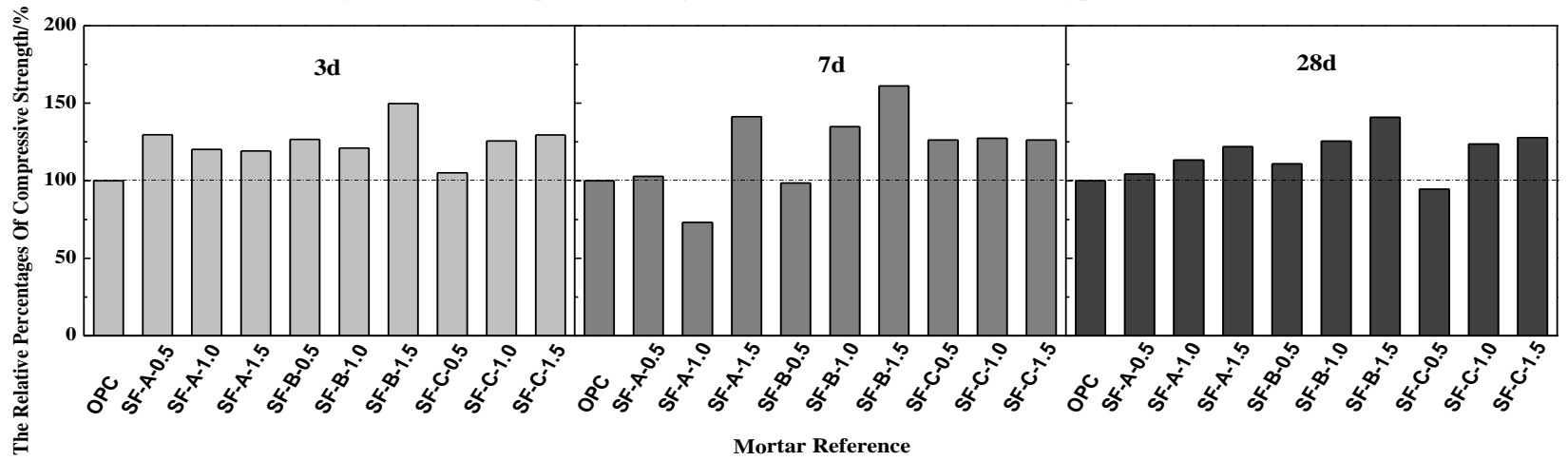

Figure 6. The relative percentages of compressive strength of cement mortar with different types of steel fiber 
C-1.5 was $16.9 \mathrm{MPa}, 154.0 \%$ higher than OPC. The results showed that the improving of matrix's strength had advantage to improving the flexural strength and toughness of mortar. Because it was conducive to give full play to the tensile strength of steel fiber [9], so that the bending damage of mortar turned the phenomenon of pulling out steel fibers to the phenomenon of pulling off steel fibers.

\section{Compressive strength}

As shown in Fig .5 and Fig .6, when the age was 3d, the compressive strength of OPC was $18.9 \mathrm{MPa}$. The compressive strength of steel fiber reinforced mortar was greater than OPC, and the compressive strength of SF-B1.5 was the maximum value, $28.3 \mathrm{MPa}, 49.7 \%$ higher than OPC. The fiber type and blended rate had little effect on the rest mortar.

When the age was $7 \mathrm{~d}$, the compressive strength of OPC was $30.9 \mathrm{MPa}$. The compressive strength of mortar mixed with type-A and type-B at blended rate of $0.5 \%$ was closed to OPC. And with the increase of fiber content, the compressive strength was increasing. In particular, the compressive strength of SF-B-1.5 was the maximum value, $49.8 \mathrm{MPa}, 61.1 \%$ higher than OPC. The content of steel fiber had little influence on the compressive strength of mortar mixed with type-C, and the compressive strength values were about $39 \mathrm{MPa}$.

When the age was $28 \mathrm{~d}$, the compressive strength of OPC was $43.2 \mathrm{MPa}$. The compressive strength of mortar mixed with steel fibers was all higher than OPC, and showed an increasing trend as the increasing of fiber content. The compressive strength of SF-B-1.5 is $60.9 \mathrm{MPa}$, $40.9 \%$ higher over OPC, followed by the SF-C-1.5, 55.2MPa, SF-C-1.0, 54.2MPa. And both compressive strength values of SF-C-1.5 and SF-C-1.0 were about $23 \%$ higher than OPC.

This experiment showed that steel fibers could improve the compressive strength of cement mortar, and the steel fibers of type-B at blended rate of $1.5 \%$ had the greatest contribution to the compressive strength of the mortar. The strength of mortar mixed with type-C(modified in laboratory) got about $20 \%$ higher than OPC at $1.5 \%$ and $1.0 \%$.

\section{CONCLUSION}

This paper study the impacts of the steel fibers' ends structure and volume ratio on the mechanical properties of cement mortar, and the results showed that:

(1) Among the three kinds of cement mortars mixed with different steel fibers, the apparent density of mortar mixed with type-C was the minimum, and turned out a steady growth trend as increasing of volume ratio.
(2) The flexural strength of cement mortar mixed with steel fibers was significantly higher than OPC. In the early, the type of steel fibers had little effect on the flexural strength, and the volume ratio played a major role on it. When the age was $28 \mathrm{~d}$, the flexural strength of mortar mixed with type-C got the maximum. Its flexural strength got $83.1 \%$ higher than the same volume fraction of type-A, and $43.6 \%$ higher than type-B, showing a strong "anchor" performance.

(3) The contribution on the compressive strength of the steel fiber' type and volume ratio was small. Of the three types of mortar, the compressive strength mixed with type$B$ got a higher value. In the age of $28 \mathrm{~d}$, the compressive strength of mortar mixed with type-B got the highest value, $60.9 \mathrm{MPa}, 40.9 \%$ over the same age of OPC at blended rate of $1.5 \%$.

(4) Based on the above content, the flexural properties of mortar mixed with type- $\mathrm{C}$ would be further improved with the increase of mortar matrix' strength. For the tensile, flexural properties of high strength concrete, improving its toughness and bending performance requires more steel fiber's content than ordinary concrete [9-10].

\section{REFERENCES}

[1] Zhao Jun, Gao Dan-Ying, Zhu Hai-Tang. Test study on the compressive performance of high strength concrete mixed with steel fiber. New Building Materials 2005; 1: 24-27.

[2] Yang Meng, Huang Cheng-Kui. Experimental study on steel fiber reinforced high strength concrete under uniaxial tension. Civil Engineering Journal 2006; 39 (3): 55-61.

[3] Serkan Tokgoz, Cengiz Dundar. Tests of eccentrically loaded Lshaped section steel fiber high strength reinforced concrete and composite columns. Engineering Structures 2012; 38: 134-141.

[4] Gao Dan-Ying, Tang Ji-Yu, Zhu Hai-Tang. Study on mix and basic performance of steel fiber reinforced high strength concrete. Zhengzhou University (Engineering Science) 2004; 25 (3): 46-51.

[5] Gao Dan-Ying, Zhu Hai-Tang, Tang Ji-Yu. The shear strength of steel fiber reinforced high strength concrete. Ceramic Society 2005;33(1): 82-86.

[6] Zhu Hai-Tang, Gao Dan-Ying, Xie Li, Zhang Qi-Ming. The study on the flexural toughness of steel fiber reinforced high strength concrete. Ceramic Society 2004;32(5): 656-660.

[7] Xie Xiao-Peng, Yang Guang-Jun, Gao Dan-Ying. Journal of Henan University of Science and Technology 2008;29(5): 54-56.

[8] GB/T 17671-2005, Cement Mortar Strength Detection Method (ISO). China.

[9] Li Fang-Yuan, Zhao Ren-Da. Experimental study on the fracture properties of high-strength concrete and steel fiber reinforced concrete. Concrete 2002; (8): 29-32.

[10] Yan Shao-Hua, Qian Qi-Hu, Sun Wei, Yin Fang-Lin. The stressstrain relationship under uniaxial compression of steel fiber reinforced high strength concrete. Journal Of Southeast University (Natural Science Edition) 2001;31(2):77-80. 